\title{
PESQUISA QUALITATIVA BUSCA DE EQUILÍBRIO ENTRE FORMA E CONTEÚDO
}

Pedro Demo*

DEMO, P. Pesquisa qualitativa. Busca de equilíbrio entre forma e conteúdo. Rev.latino-am.enfermagem, Ribeirão Preto, v. 6, n. 2, p. 89-104, abril 1998.

Este artigo apresenta uma descrição da mudança de expectativa no que se refere à pesquisa qualitativa através da evolução da pós-modernidade. Enfoca a qualidade sob vários aspectos apontando os usos e abusos na pesquisa qualitativa.

UNITERMOS: pesquisa, pesquisa qualitativa

Algumas evoluções da pós-modernidade em ciência trouxeram certa mudança de expectativa com respeito à pesquisa qualitativa ${ }^{25,32}$. Podemos, a título de sistematização preliminar, distinguir três fases da discussão:

a) na tradição positivista, pesquisa qualitativa não fazia muito sentido, pela própria exclusão da dialética como método importante da reconstrução do conhecimento; tomando as ciências exatas e naturais como modelo paradigmático, as ciências sociais teriam como desafio intrínseco absorver as mesmas regras; o próprio marxismo ortodoxo não escapou disso, quando exagerou na dose do materialismo histórico e dialético, selecionando, na realidade, de preferência a manifestação material ${ }^{29}$;

b) a introdução dos métodos qualitativos veio como reivindicação das ciências sociais e humanas, inconformadas com a "ditadura do método", que assumia como real apenas o que cabia no método, em vez de privilegiar a relação contrária: o método de captação da realidade deve subordinar-se às marcas da realidade; também sob a influência de discussões acaloradas em torno da fenomenologia e da hermenêutica, começou-se a falar de método qualitativo, que, de princípio, não tinha nada de mais específico, a não ser a reação contra a imposição quantitativista; com o tempo, surgiram propostas mais concretas, que passaram pela pesquisa participante, pesquisa-ação, história oral, até a atual etnometodologia $^{17,20,90}$;

c) atualmente, o debate segue outros rumos, além dos já aludidos, por conta de questionamentos radicais que a metodologia científica pós-moderna vem fazendo aos paradigmas anteriores; pelo menos em certa medida, as pretensões das ciências sociais e humanas estariam ganhando terreno, à medida que os métodos matemáticos e naturais cedem às dificuldades notórias de captar fenômenos mais qualitativos, geralmente visualizados sob a ótica do caos estruturado, não-linearidade e complexidade da realidade, não-equilíbrio, etc.

\section{A INSTABILIZAÇÃO DA CIÊNCIA}

Para sermos justos, o fenômeno da instabilização da ciência se deu no próprio seio do positivismo, tendo como um dos precursores maiores, Hume, e expoente consagrado, Popper, com sua tese da falsificabilidade como critério de cientificidade. A ciência sempre se quis como adversária da dúvida, mas só progride porque é duvidosa. Sendo seu signo principal a capacidade de questionar persistentemente, o questionamento só faz sentido num contexto de dúvida e inovação ${ }^{29,73,75}$.

Um autor importante nesta história foi Habermas, quando definiu verdade como "pretensão de validade", mesmo ligado, em grande parte ainda, à visão transcendentalista de Kant, que admite verdades independentes de espaço e tempo, inclusive no campo

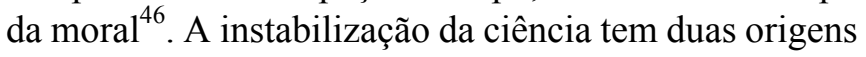
mais claras:

a) uma origem lógico-formal, com base na impossibilidade de produzir uma argumentação final para qualquer discurso científico; este reconhecimento ficou ainda mais estabelecido com o teorema de Gödel, e retratado com veemência e grande dose de ironia na tese pós-moderna de Lyotard, segundo a qual a ciência é circular, porque fundada em metanarrativas que não

* Professor Titular da Universidade de Brasília. PhD em Sociologia 
conseguem fundamentar-se a si mesmas ${ }^{57}$; com efeito, toda teoria supõe conceitos prévios, hermeneuticamente válidos, ou seja, em qualquer definição somos obrigados a usar termos não definidos;

b) uma origem política, porquanto toda pretensão de validade acaba valendo, se puder ser consensuada dentro de um contexto de discussão aberta; em certa medida, democracia do questionamento passa a fazer parte dos critérios de cientificidade, mas em estreita combinação com os lógicos; um discurso será tanto melhor questionável, quanto mais bem elaborado for, em termos formais.

À diferença de Popper, que instabiliza a ciência por razões apenas lógicas - é impossível logicamente buscar fundamentação última dedutiva, bem como toda indução acarreta uma regressão ao infinito por não poder observar todos os casos concretos possíveis -, Habermas acrescenta o argumento histórico, admitindo que a ciência é o produto da atividade dos cientistas, não algo desencarnado, embora deva sempre ter marcas formais inequívocas. Usa em sua argumentação, buscada em Apel, a figura da "contradição performativa", segundo a qual não se pode desfazer, no discurso, a própria possibilidade do discurso. Assim, se admitirmos que o questionamento é a alma da ciência, não é viável imaginar um questionamento inquestionável ${ }^{24}$.

Embora este argumento seja apenas relativo, porque, como toda asserção lógica, não tem fundação última ou incorre em contradições circulares, além de negligenciar o contexto histórico, reforçou um princípio fundamental da pós-modernidade, que é o ímpeto desconstrutivo do conhecimento, razão maior de sua voracidade inovadora. Só pode ser científico, o que for questionável, formal e politicamente.

O conhecimento é tão inovador hoje, porque estabilizou sua instabilidade no plano do método. Ou seja, inova porque saber inovar-se. Não é como, por exemplo, a universidade, que fala de inovação e até mesmo se define como instituição a ela dedicada, mas não sabe inovar-se, permanecendo a mesma velharia secular. Não há como inovar, permanecendo o mesmo. $\mathrm{O}$ ímpeto desconstrutivo do conhecimento não significa, de modo algum, coisa boa, pois agride a tessitura hermenêutica da história e do ser humano, culturalmente plantado. Não podemos nos desfazer todo dia, para nos inventar de novo, como se não houvesse história. Entretanto, não é viável inovar, sem nos desconstruirmos pelo menos em certa medida. Este desafio a universidade não está sabendo deglutir, e por isso vai se tornando uma entidade de resistência, cada vez mais fora do tempo, enquanto o mercado está se dando bem com o conhecimento $^{33,82}$. A competitividade alimenta-se da produção e uso intensivo do conhecimento, residindo nisso o diferencial de desenvolvimento entre os povos.
Com base em conhecimento - ou na mais-valia relativa, na linguagem marxista ${ }^{89}$ - é possível produzir melhor e mais barato, mesmo que às custas do emprego. $\mathrm{O}$ desemprego estrutural é resultado direto do conhecimento desconstrutivo e inovador.

O conhecimento inovador, de ponta, está fugindo da universidade, porque esta não sabe desconstruir-se, ou seja, inovar e educar a inovação. O mercado fica apenas com a qualidade formal, enquanto a universidade deveria agregar a qualidade política, sobretudo porque esta é o fim e a ética do conhecimento.

A instabilização da ciência obteve impulso da interdisciplinaridade. Este teve também duas origens principais:

a) uma origem no método, sobretudo na especialização metodológica, que leva a saber cada vez mais de cada vez menos; ao final, temos o "idiota especializado", tornando-se o mundo científico um circo ininteligível, por conta das linguagens particulares e as compartimentalizações acadêmicas; não se trata apenas da difícil compreensão dos discursos, mas sobretudo do fechamento disciplinar, que produz uma espécie de "cegueira", como quer Morin, à medida que, olhando somente para certa coisa, não consegue ver nada mais além disso ${ }^{67,68}$;

b) uma origem na complexidade do real, reconhecendo que a realidade é mais complexa do que as simplificações metodológicas usadas em sua captação; isto levou a reclamar a organização interdisciplinar de grupos de pesquisadores, buscando um meio termo entre especialidade - sempre inevitável para ser a análise profunda - e compreensão de uma realidade que nunca é especial, mas apenas complexa.

Alguns bestsellers na esfera dos estudos da inteligência empurraram bastante a discussão, chamando a atenção, por exemplo, para a importância da emoção e do sentimento. Gardner defende as "inteligências múltiplas" e combate o tipo de mensuração implicado no $Q I$, que privilegia apenas o domínio formal-lógico do pensamento. Goleman e Damásio procuram ultrapassar o more geometrico de estilo cartesiano, incluindo na razão também o que seria pelo menos tão característico do ser humano quanto a racionalidade, a emoção. Todos estes autores praticam uma pesquisa intensamente interdisciplinar, englobando a investigação biológica clássica ao lado de todas as implicações tipicamente hermenêuticas das ciências humanas ${ }^{19,38,43}$.

As discussões mais acaloradas, entretanto, provêm da física e da biologia, seja pela via das teorias do caos e da não-linearidade matemática, seja pela via da reação construtiva nos seres vivos em geral. Tem realce Prigogine, que, entre outras novidades, passa a aceitar na matéria certa noção de tempo e irreversibilidade, concedendo que a criatividade - sempre vista como 
monopólio humano - também é componente da matéria, pelo menos em certas circunstâncias. O mundo está em formação. Logo, não é totalmente formalizável e sua evolução não pode ser prevista matematicamente. Uma "teoria de tudo" é impraticável. O paradigma muda de direção: em vez de explicar a desordem sobre um pano de fundo de ordem, a ciência precisa explicar como é possível a ordem no caos ${ }^{6,66,78}$.

Maturana inaugurou na biologia o conceito de "autopoiesis" - autoformação - para indicar a característica de todo ser vivo de poder reagir, em seu meio, de maneira reconstrutiva, e não apenas passiva, como estaria dito no "reflexo condicionado". Talvez tenha sido esta a contribuição mais forte contra a tradição escolar do "treinamento", em apoio às teses de Piaget, por exemplo ${ }^{61,62}$. A aprendizagem passou a ser vista como marca eminente do ser vivo, sobretudo do ser humano, e implica sempre um esforço reconstrutivo. Muitas das críticas feitas hoje à aula meramente expositiva, à atitude professoral de falar diante de um aluno que escuta, toma nota e faz prova, provêm dessa visão confirmada na biologia. $\mathrm{O}$ aluno somente aprende se pesquisa e reconstrói conhecimento com mão própria, tendo no professor o exemplo de quem aprende bem, não de quem apenas dá aula.

\section{O LEGADO FORMAL}

Toda esta discussão, entretanto, não destruiu o legado formal da ciência, como se fosse possível fazê-la sem lógica. Apenas o colocou sob outra luz.

A primeira conclusão foi ter de aceitar que a ciência é apenas um olhar sobre a realidade, e nem sempre o mais adequado. Boaventura dos Santos trabalhou esta perspectiva com base na ruptura epistemológica de Bachelard, mostrando uma artificialidade típica do conhecimento e pleiteando a volta do conhecimento para o bom senso e mesmo para o senso comum, que são, afinal de contas, o conhecimento que orienta as pessoas no $\operatorname{cotidiano}^{84}$.

A segunda conclusão foi a de reconhecer que tal seletividade metodológica pode facilmente reinventar a "ditadura do método" sobre a realidade, considerando real apenas o que cabe no método de captação. Na prática, a ciência se interessa pela face formalizável da realidade, expurgando tendencialmente as outras. Por isso mesmo, quando quer "medir" a inteligência, seleciona nela indicadores quantificáveis, de preferência a outros.

A terceira conclusão foi a de reconhecer ademais que o legado formal não poderia, pelo menos por enquanto, ser abandonado. A ciência abusou dele, mas lhe é parte essencial. Neste sentido, destaca na realidade as manifestações mais facilmente formalizáveis, o que já traz um prejuízo claro frente ao que costumamos chamar de qualidade. O legado formal é, assim, virtude e vício ao mesmo tempo.

É vício, por tender a distorcer a realidade, na proporção em que compreende melhor o que é sistematizável logicamente. É virtude, porque consegue captar com grande proficiência as faces formais. $\mathrm{O}$ progresso da ciência é algo inegável e fantástico.

Por conta disso, Prigogine fala de caos "estruturado", já que uma realidade propriamente caótica é inatingível pela ciência. Somente se compreende aquilo que puder ser minimamente sistematizado, ou seja, se não houver no fenômeno nada que tenha perfil lógico, sistemático, recorrente, pelo menos regular, não pode ser abordado cientificamente. Por isso mesmo, a ciência trabalha melhor quantidades do que qualidades. Estas estão definitivamente reconhecidas, e são, de novo, moda, mas são mais complicadas de serem manejadas pela pesquisa científica.

Convém, desde logo, fazer uma distinção importante. A resistência que a pesquisa científica manifesta frente a realidades qualitativas não precisa ser apenas tradicionalismo positivista. No fundo, é uma resistência natural, que advém de sua tessitura formallógica. Quando os novos pesquisadores da inteligência buscam, sofregamente, realçar a emoção, por exemplo, enfrentam dificuldades oriundas da formalidade científica, que, de virtude, pode virar defeito, ao amarrotar faces essenciais, mas menos formais, dos fenômenos. Mesmo assim, nos fenômenos mais voláteis, dispersos, contraditórios, fragmentários etc., a ciência parte sempre para visualizar neles o que houver de formalizável, antes de mais nada. Também por isso, a qualidade é captada na contra-luz de expressões quantitativas, ou na greta dos $\operatorname{dados}^{23}$.

Temos na história da ciência exemplos relevantes, sobretudo a descoberta de Freud de que os sonhos, aparentemente caóticos e assim considerados por muitos, são sistematizáveis, desde que se faça uma análise em profundidade. Assim, sonho não é um monte incoerente de coisas, mas um caos estruturado. A ciência não sabe $o$ que fazer daquilo que é propriamente caótico, mas começa a entender o caos, se descobrir nele alguma estrutura.

Marx também pode servir de exemplo, em seus momentos mais ortodoxos, quando procurou secundarizar a super-estrutura, composta de ideologias, vontades, consciências, em favor da infra-estrutura material, e que seria, por sinal, mais devassável cientificamente ${ }^{59}$. Este vento "positivista" é inegável em obras da velhice e é à base dele que imaginava estar descobrindo "as leis da história" e que, como diz no prefácio do $1^{\circ}$ volume de $\mathrm{O}$ Capital, seriam "férreas", para sinalizar que determinam a história, como uma causa física determina um efeito 
físico. Nisto via sua cientificidade. Althusser inventou, à sombra dessa visão, o anti-humanismo de Marx, para dizer que, ao analisar a realidade, não contava a consciência humana, mas a determinação material objetiva. E Lévi-Strauss sempre considerou Marx seu precursor, porque deu maior importância à inconsciência, do que à consciência, e por, conseqüência, à intervenção humana histórica ${ }^{29}$.

Este tipo de consideração parece decisivo, porque é preciso desfazer a banalização recorrente na pesquisa qualitativa frente aos desafios da formalização científica. Por exemplo, é comum ouvir-se que método já não seria muito importante, até porque vai se inventando pelo caminho. A par da incoerência de não perceber que falta de método também é um deles, porque é inviável fazer sem um modo de fazer, perde-se de vista aquilo que a ciência sabe propor melhor, ou seja, traduzir uma realidade em suas formalidades possíveis.

Dentro desse contexto, também já não cabe combater a quantidade, porque é parte constituinte de qualquer qualidade, e vice-versa. Dito de outra forma, toda qualidade, por mais volátil que seja, admite alguma formalização, e é isto que a ciência poderá oferecer de útil. Na pesquisa qualitativa também é mister saber definir termos, precisar a hipótese de trabalho** como roteiro reconstrutivo abertamente direcionado, construir bases teóricas, selecionar relevâncias, e assim por diante, todas atividades no fundo lógico-formais. Caso contrário, vendemos a pesquisa qualitativa como diletantismo e, na prática, incompetência metodológica.

Dito isto, cabe destacar a intenção própria da pesquisa qualitativa, que é perseguir faces menos formalizáveis dos fenômenos, às quais damos o nome de qualidade. Um dos problemas mais agudos dessa questão é a indefinição de qualidade, já que nela cabe tudo e nada, ao sabor de qualquer coisa, tornando as pesquisas qualitativas experimentos excessivamente tópicos e inconclusivos. O "fim das certezas", como quer Prigogine, ou as "ciências do impreciso", como quer Moles, não lançam sobre o conhecimento um "vale-tudo", como se qualquer discurso pudesse, agora, tornar-se científico por auto-decreto. Ao contrário, isto torna o métier científico tanto mais árduo, por conta da fragilidade intrínseca de sua argumentação. Se foi um ganho enorme o reconhecimento de que a verdade também é processo histórico de construção e desconstrução humana, continua de pé que não é factível o argumento bem posto sem perfil lógico. É mister combinar bem lógica e democracia, e não sacrificar uma à outra, conservando ademais que qualidade política é fim, enquanto a formal é meio ${ }^{72}$.

\section{DEFININDO TENTATIVAMENTE QUALI- DADE}

Buscamos aqui apenas definir preliminarmente o conceito de qualidade, com o objetivo de ultrapassarmos dois problemas:

a) de um lado, a definição exclusivamente negativa, que somente diz o que qualidade não é (não é quantidade);

b) de outro, o ambiente de penumbra conceitual em que comumente é tomado.

Com efeito, na maioria das vezes assumimos qualidade como aquela dimensão - essencialmente vaga - que representaria o contrário de quantidade, ou que estaria além da quantidade. Outras vezes, toma-se o conceito como evidente, sobretudo após o modismo da "qualidade total"41,42. De nossa parte, consideramos complexo definir adequadamente o conceito de qualidade, não só porque nenhum conceito é evidente, mas sobretudo porque assinala dimensões da realidade que são tão essenciais, quanto imprecisas. Ninguém duvida que qualidade existe, tanto porque o horizonte material nunca é tudo, embora muitos julguem ser o principal, quanto porque fazem parte da experiência comum horizontes que desbordam o mundo quantitativo, como felicidade, ética, compromisso político, etc. Todavia, é muito difícil dizer - positivamente - o que, afinal, é qualidade.

Por outra, não faz sentido apostar na dicotomia entre quantidade e qualidade, pela razão simples de que não é real. Pode-se, no máximo, priorizar uma ou outra, por qualquer motivo, mas nunca para insinuar que uma se faria às expensas da outra, ou contra a outra. Todo fenômeno qualitativo, pelo fato de ser histórico, existe em contexto também material, temporal, espacial. E todo fenômeno histórico quantitativo, se envolver o ser humano, também contém a dimensão qualitativa. Assim, o reino da pura quantidade ou da pura qualidade é ficção conceitual. A própria "qualidade total" está enredada nesta trama complicada. É comum bastar-se com quantidades insatisfatórias, como cursos que não vão além de treinamentos, por vezes relâmpago. Como é comum aceitar qualidade como certas "lavagens cerebrais", que

\footnotetext{
** A prevenção comum entre pesquisadores qualitativos contra "hipótese de trabalho" como se fosse ardil positivista, já denota a unilateralidade de posição. Hipótese de trabalho é componente útil de todo processo de pesquisa, quantitativa ou qualitativa, e indica apenas um lançamento prévio e sempre aberto de roteiro de trabalho. De modo algum está necessariamente implicado positivismo em quem usa este conceito, como também não está implicada posição revolucionária em quem usa a dialética. $\mathrm{Na}$ prática, a maioria dos que se dizem dialéticos não saberia definir o que é dialética e sobretudo de que dialética se trata
} 
cultivam encontros muito emocionalizados, cujo resultado principal é o adesismo. "Fazer a cabeça", por exemplo, será competência de quem se impõe, mas é sempre incompetência de quem aceita.

\section{A) Aproximações categoriais}

Num primeiro passo, podemos apelar para a etimologia latina: em latim, qualitas significa a essência. Assim, qualidade designa a parte essencial das coisas, aquilo que lhe seria mais importante e determinante. Se olhássemos ainda para o legado filosófico aristotélico, a distinção entre matéria e forma destaca, na forma, aquela dimensão imaterial dos seres e que, nos seres humanos, seria imortal. A forma é a definição central, enquanto a matéria seria algo circunstancial, temporal, provisório ${ }^{36}$.

Neste sentido, qualidade aponta para a marca central das coisas e dos seres, aquilo que não se consome no tempo, que fica para sempre, que decide o que algo é definitivamente. Esta visão ainda é certamente vaga, porque é muito complicado decifrar o que "algo é definitivamente". Quando se fala em essência, temos talvez a certeza de que se trata de coisa muito relevante, mas, ao mesmo tempo, não sabemos muito bem o que é.

Num segundo passo, qualidade aponta para a perfeição historicamente possível sobretudo do ser humano ou da história. Nesta maneira de ver, já abandonamos a aplicação do conceito a tudo, reservandoo para o fenômeno histórico, e sobretudo ao fenômeno humano. Ao mesmo tempo, não sendo perfeição apenas algo dado, mas principalmente construído na história, trata-se de apanhar aqueles fenômenos que representariam conquistas históricas consideradas desejáveis ou que expressam realização humana relevante.

Tratando-se de história, não há perfeição, já que não tem história o que é perfeito. Condição para ser histórico, é ser perfectível. Neste sentido, quando falamos de perfeição, assinalamos basicamente o esforço histórico para realizar uma história sempre mais perfeita, desejável, solidária, participativa, etc. Neste sentido, qualidade é sobretudo participação, se aceitarmos que a história participativa seja aquela que mais próximo chega da sociedade desejável. Talvez pudéssemos até aventar que participação poderia ser sinônimo de qualidade ${ }^{21}$.

Tal contexto nos permitiria trabalhar também com o conceito de utopia, no sentido de construção humana negativa que faz parte da realidade. Como o próprio termo indica, utopia não se realiza. Utopia realizada já não é. Entretanto, faz parte da realidade como dialética do contrário, ou seja, como fonte perene da crítica contra aquilo que se tornou real. Frente às esperanças absolutas da utopia, o que a história oferece é sempre pouco e, por conseqüência, cabe sempre a revolução. Tomando um exemplo concreto: a utopia do socialismo representa aquela sociedade perfeita que, por definição, não pode acontecer; entretanto, é por conta desta perfeição impossível que podemos criticar e superar todos os socialismos reais, na certeza de que nenhum deles esgota a utopia do socialismo. Por isso, diz-se que, quem não tem utopia, morreu, já que se contenta com o que tem, ou com o que a história conseguiu realizar.

Qualidade representaria a utopia da história, no sentido daquilo que de melhor o ser humano nela poderia realizar. Olhando a história concreta, não seria difícil apontar que participação será um desses fenômenos que representaria esta utopia ${ }^{5,34}$. Pode ser traduzida como comunidade, democracia, associativismo, irmandade, solidariedade, etc., fenômenos marcados pela igualdade das pessoas, ou pela equalização das oportunidades, ou pela inclusão de todos. A história conhecida jamais realizou uma sociedade dotada desta perfeição, e mesmo assim persiste, de modo teimoso e insistente, a utopia da igualdade, por exemplo. Muitos diriam que a desigualdade social é algo histórico-estrutural, porque faz parte estrutural da história ${ }^{54}$. Como estrutura, aparece em toda história. Como história, pode ser mudada em cada história. Exatamente este dinamismo dialético faz a história como unidade de contrários ${ }^{29}$.

Ao mesmo tempo, falando de perfeição, existe sempre o outro lado, da imperfeição. Haveria, pois, uma maneira de realizar as coisas de modo mais e menos perfeito, o que poderia ajudar a localizar melhor o que seria qualidade. Assim, existe educação com e sem qualidade, designando, no lado negativo, maneiras indesejáveis, inaceitáveis, imperfeitas de educar, e, no lado positivo, maneiras consideradas adequadas, criativas, convincentes. No lado negativo, teríamos "deseducação" a título de educação, como é o caso do baixíssimo rendimento escolar no Brasil. No lado positivo, teríamos a realização mais convincente daquilo que seria a essência da educação, como a emancipação, a formação da competência humana na história, a cidadania ${ }^{25,27,28}$.

Num terceiro passo, qualidade sinaliza o horizonte da intensidade, para além da extensão. Significa outra dimensão fundamental de fenômenos qualitativos que é sua busca de profundidade e plenitude. Corre-se, certamente, o risco também de, de novo, inventar uma dicotomia entre os dois termos, o que não é real $^{12,44,45,65}$. Se tomarmos o problema dialeticamente, quando dizemos que algo é o contrário, estamos ipso facto apontando para um todo com duas faces. Não se trata de coisas contraditórias, ou seja, que não admitem dinâmica entre elas. Trata-se exatamente do oposto: somente coisas contrárias são dinâmicas, porque existem na polarização. Assim, se dizemos que intensidade é o contrário de extensão, não estamos dizendo que uma exclui a outra, mas que há entre elas uma dinâmica contrária, de teor tipicamente dialético ${ }^{22,29}$. 
Por conta disso, pode-se armar com os dois termos um quadro bem representativo da realidade histórica, na medida que intensidade denota dimensões tais como:

a) fenômenos que não se esgotam no superficial, mas marcam-se pela profundidade, como o amor;

b) fenômenos que reagem à rotina extensa e, por isso, buscam renovar-se sempre, como a felicidade;

c) fenômenos que primam pela dinâmica do compromisso, como é o engajamento político, ou a militância;

d) fenômenos que indicam a plenitude da realização humana, como é a santidade;

e) fenômenos que valorizam participação humana, mais que a mera presença física ou quantitativa, como é o envolvimento comunitário, a democracia, a cidadania; f) fenômenos que apontam para dimensões valorativas do ser humano ${ }^{1}$, como a dedicação, a ética, a abnegação, o envolvimento, a prestatividade, a solidariedade, etc.

A intensidade aponta para a dimensão do melhor, enquanto a extensão se volta para o maior. Ter mais ou ser melhor por vezes representam uma disjuntiva, que, na prática, deveria ser um todo: quantidade a serviço da qualidade, ou como condição material de qualidade. A sabedoria da felicidade está em transformar o passamento extenso em passagem intensa. Pois nenhuma solução é total, e o homem como problema não tem solução, pois não é defeito, mas modo de ser. Nisto precisamente é desafio, pretensão, ânsia, afã. A história é passageira, mas em cada fase não acaba; ao contrário, continua. Continua sempre, não porém como continuidade contínua, mas como eterno recomeço. No plano formal, algo contraditório. Na história real, apenas contrário. Toda superação é também recomeço. Não há solução final e definitiva, pelo que não se pode imaginar felicidade eterna, que já seria extensão da monotonia.

Ao se vencer um desafio, vem o próximo; ao se realizar um ideal, surgem outros. Continuidade extensa é a morte. A morte é a extensão mais monótona que a história conhece. Se toda revolução, de um lado, envelhece, a partir de dentro, como regra da vida, por outro, aí mesmo elabora seu recomeço ${ }^{60,76}$. Pois todo clímax é passageiro, por mais que o desejemos eterno. Eternidade não vem compreendida como continuidade da mesmice, na horizontalidade estável, mas como auge da intensidade. Verticalmente eterno é o momento total, não por durar sempre, mas por buscar esgotar a profundeza da intensidade no momento da passagem. É o momento que vale tudo, tão intenso que é possível "morrer de felicidade". A vida toda vale este "instante total". Na história, não interessa a eternidade como linha reta, sempre a mesma, formal e fria, mas a curva dinâmica em busca do ápex. Este é apenas o momento mais alto um só -, mas define seu alcance. A felicidade realiza os dois momentos marcantes de sua intensidade: a passagem pelo clímax - intenso e efêmero - e a seguir o recomeço da nova fase. Por isso o momento profundo é o autêntico processo, como processo de recomeço, onde a passagem não se pulveriza na insignificância, mas se eterniza na violência da intensidade. Qualidade não é sólida; é frágil. Não tem resistência dura daquilo que se petrifica. É passageira, para retornar. Recriar é seu signo. Só se recria, o que passa. O melhor é sempre mais passageiro.

A vida tem sua sabedoria no equilíbrio contrário entre desejos infinitos e realizações parciais. O prazer sexual é um exemplo: por mais forte que seja o desejo, também satura. Mesmo divertir-se pode ser cansativo. É fundamental variar. Todavia, a surpresa não pode ser diária, pois já não surpreenderia, mas é essencial. $\mathrm{O}$ orgasmo é por definição passageiro, pois é gesto fisicamente limitado. Na sua passagem pode ser intenso, profundo, totalizante. Mas não é factível sua continuidade extensa, tanto por impossibilidade física, como sobretudo porque quebraria seu encanto. É lei da vida: após o clímax vem inevitavelmente a calma. Esta é que dura, o outro passa. É possível inventar modos e jeitos para prolongar o prazer, mas é sobretudo importante poder recriá-lo. Passagem criativa, que passa, não para desaparecer, mas para reviver. Esta é a eternidade que interessa; a outra aborrece $^{9,14,16,49}$.

Diante dos desejos infinitos, não há solução cabal. Há propriamente pactos. Porquanto, toda solução reencontra novos problemas e toda fase propicia a seguinte. Esta cisão é fundamental para se compreender o ser dialético. Tem a constituição de problema estrutural. Assim, em parte não é problema, pois, sendo problema na estrutura, não é problema histórico, mas condição dada. A limitação histórica não é limite, porque tal incompleição não é falta, mas marca. A unidade de contrários está na sua alma. Não é acidente, descuido, nem degeneração, mas modo melhor de ser. Em conseqüência, não pode haver receita definitiva da felicidade, por mais que nela se reconheçam lógicas. Felicidade é arte, criatividade. É sabedoria, que provém sobretudo da prática irrepetível. Se é variação, passagem, seria contraditório querer receita da qualidade, porquanto teríamos que inventar a receita da não-receita. Como garantir a continuidade invariante do que é essencialmente provisório? Não se pode, a rigor, programar o improviso. A intensidade também se alimenta da surpresa.

A felicidade tem a lógica da flor: não há como separar sua beleza da fragilidade e do fenecimento. Entretanto, o fenecimento não é apenas a destruição de sua beleza, mas condição de recomeço. Assim, deve-se aceitar que a flor é bonita porque fenece. Flor que fica sempre é de papel, artificial. É cópia. A flor viva vive a contrariedade da vida: desgasta-se, passa. A seguir, brota de novo. A felicidade possui o frenesi do desejo eterno 
na sua estrutura, mas realiza-se na passagem intensa de um momento na sua história. Ser feliz é multiplicar momentos felizes. Ou: saber deglutir a infelicidade, que é diária, para saborear melhor a felicidade, sempre que for possível. Felicidade, não se passa por ela. É ela na passagem. A maior infelicidade é querer a felicidade total, toda hora. Todo amor acaba traído. Dói. Mas recomeça $8,11,18,39,40,48,56,83,85,87,88$.

Olhar a qualidade a partir da ótica da felicidade pode induzir a restringir o desafio ao plano pessoal ou psicossocial. Para nossos fins aqui, o realce maior estará ligado ao horizonte político do ser humano, no qual o repto central não é ter mais, mas ser melhor. Trata-se de visualizar a história como obra coletiva, na qual, principalmente sob o horizonte da cultura e da identidade cultural, o ser humano comprova que é capaz de fazê-la, ou seja, de fazer e fazer-se oportunidade. Certamente, não podemos destruir o contexto dialético da história, quer dizer, qualidade política não expressa apenas o lado bom, não só porque este não está sozinho, mas sobretudo porque tende a ser minoritário. A história conhecida propende muito mais a ser um ato de afirmação excludente, do que de solidariedade ilimitada. Assim, na cultura de cada povo não está escrito apenas a comprovação histórica de sua competência em identificarse, sobreviver e fazer uma sociedade, mas igualmente de conquistar espaço próprio e de se impor. Por isso, quando falamos de competência história, a tendência é interpretála como conquista que se impõe. Ao dizermos, entretanto, "competência humana", buscamos ressaltar a história solidária.

O realce do horizonte político da qualidade nos leva a enfocar expressões histórico-culturais marcadas não só pelo progresso técnico e econômico, mas sobretudo por sua humanização, como desafio eterno de uma obra por definição inacabada. Podemos ressaltar:

a) fenômenos históricos relevantes são conquistas como a democracia, a cidadania, os direitos humanos, a participação, a comunidade organizada, etc.; expressam o tipo mais qualitativo de cada sociedade, porque não só apontam para a competência de se organizar, mas sobretudo para a competência de participar, dentro do desafio de construir uma sociedade cada vez menos desigual;

b) ao mesmo tempo, tais fenômenos marcam-se pela fragilidade histórica: são tão bonitos, quanto fugazes; facilmente viram no contrário (democracia como tática de acumular privilégios, cidadania corporativista, comunidades beligerantes, etc.); é difícil construí-los, e mais ainda mantê-los; a expressões mais qualitativas, como profundidade, intensidade, envolvência, participação, são, por definição e história, passageiras; c) a ambiência naturalmente ideológica revela, por sua vez, a marca dialética mais íntima: pode servir para o bem e para o mal, a solidariedade atrai menos que a influência, a ética não comparece como dada, mas apenas como dura e frágil conquista, há sempre uma distância marcante entre o que cada sociedade promete ser e o que é de fato, e assim por diante;

d) todo ser humano é uma potencialidade, por ser um fenômeno intrinsecamente político; ele é o artífice central de sua própria obra história, mas não está sozinho no mundo; para desabrochar, é mister ainda que existam circunstâncias dadas favoráveis, bem como um ambiente humano receptivo; politicamente falando, a lógica dialética do poder propende a privilegiar o mais forte, $\mathrm{o}$ mais rico, o mais sagaz, do que o mais humano;

e) são fenômenos marcantes da qualidade humana as expressões da arte, da estética, da sensibilidade, da cultura, mais do que os resultados ditos civilizatórios, que refletem o progresso como imposição e como espaço material; ao mesmo tempo, representa arte humana crucial saber transformar o progresso em bem comum, realizando um dos traços mais profundos do que podemos chamar de competência humana;

f) para resumir, qualidade essencial é a competência de tornar cada vez mais humana a história do ser humano.

\section{B) Qualidade Humana}

Os três passos anteriores levam a admitir, desde logo, algumas características da qualidade, sobretudo quando assumida como qualidade humana. A ONU acabou admitindo a idéia de "desenvolvimento humano", sinalizando que as outras adjetivações (social, econômico, ecológico, etc.), seriam melhor representadas pela marca humana. Com isto ficou também superado, pelo menos até certo ponto, o conceito de "qualidade de vida", que muitas vezes não consegue explicitar-se de modo suficiente, seja porque denota quase apenas horizontes quantitativos (salário, moradia, condições sanitárias, transporte urbano, etc.), seja porque descamba facilmente em dicotomias contra a "quantidade de vida".

Pode-se usar o termo, assim mesmo, mas parece claro que o conceito de desenvolvimento humano, mesmo provindo de ambiente neoliberal, é muito mais rico, sobretudo porque expressa a construção e a conquista da competência histórica humana. Não é dada. É tipicamente conquista. Ou, como diz a ONU, é "oportunidade". Pode ser feita, melhorada, conquistada, bem como obstaculizada, destruída, esquecida. A qualidade humana essencial seria aquela que expressa a competência histórica em dois momentos de conquista substancial: fazer-se sujeito, deixando a condição de objeto ou de massa de manobra, e, a partir daí, fazer história alternativa, marcada pela eqüidade e pela ética $^{26,72}$

Diante disso, podemos assinalar alguns horizontes que caracterizam a qualidade. 


\section{Qualidade é atributo humano}

Somente o ser humano é capaz de qualidade, pois trata-se de um fenômeno histórico-dialético. A matéria não teria qualidade, a não ser aquela que fosse dada, ou tomada como algo dado ${ }^{2,53,63,64,91}$. Poder-se-ia dizer que um diamante tem mais ou menos qualidade, dependendo de sua pureza. Há aqui uma questão de perfeição, mas que não é conquista humana histórica.

Por ser atributo humano, qualidade é função precipuamente da educação, já que educação é o caminho crucial da competência histórica. Para o ser humano ter oportunidade e sobretudo ser oportunidade, necessita construir a competência mais radical que existe, que é a de fazer-se sujeito. Não é à-toa que a ONU, ao classificar os países de acordo com o desenvolvimento humano, coloca, entre os três indicadores usados, a educação em primeiro lugar. $\mathrm{O}$ que melhor trabalha o horizonte das oportunidades e principalmente torna o ser humano oportunidade é o processo educativo, desde que seja emancipatório $^{50,58,86}$. A seguir vem o indicador da expectativa de vida, que mistura sabiamente traços quantitativos (anos de vida) com qualitativos (desfrute da vida). E por fim aparece o indicador material propriamente dito, que é o poder de compra. Está assinalado aqui que o desenvolvimento humano é basicamente questão de qualidade, não só de quantidade. Ou seja, é sobretudo questão de ser, não de ter, por mais que entre ambos não se possam inventar dicotomias.

Com isto já se aposta numa direção clara: quando se busca qualidade em qualquer instituição, o que temos de trabalhar melhor são os seres humanos envolvidos, ou como se diz na qualidade total, os "recursos humanos ${ }^{\$ 47,77,79,80,81}$. O que faz a qualidade de uma escola não são a parabólica, ou a videoteca, ou os computadores, mas o naipe de profissionais nela engajados.

\section{Qualidade é dialética}

A dialética humana é da unidade de contrários, encontrando aí sua dinâmica histórica própria. Faz parte desta lógica polarizada, entre outras coisas:

a) tudo que é profundo, é passageiro; a intensidade transforma-se em extensão, se perdurar; vira rotina; a profundidade tem a lógica do momento, e no momento pode ser avassaladora, total, plena, não na extensão esticada; ser passageiro denota, ao mesmo tempo, a fugacidade da vida, mas sobretudo sua maneira própria de ser; passar não é vicissitude, é essência;

b) o que é bom, acaba; o bom extenso, enjoa, satura, enoja; acabar é condição de qualidade, para não se esvair na rotina, que a tudo mata, porque não deixa passar; a coisa mais histórica que a história conhece é o desgaste no tempo; qualidade é a capacidade de se confrontar com este desgaste, impondo ao tempo, no momento, a intensidade que a extensão nega;

c) a criatividade é uma dinâmica provisória, não uma situação definitiva; a criação mais profunda do ser humano não é uma sociedade acabada, mas por se fazer; toda instituição envelhece; por isso, viver é, essencialmente, renovar-se; quem se renova não deixa de envelhecer - isto é implacável para um ser histórico - mas impõe à extensão temporal momentos de criatividade intensa***;

d) utopia é o afrontamento dos limites, dentro dos limites; buscamos a perfeição, sabendo que nenhuma história é perfeita; a perfeição da história é a oportunidade possível de aperfeiçoá-la; só pode ser momentânea a sensação de plenitude, dentro de uma história que não pode jamais ser plena; qualidade é essencialmente uma esperança, que vale sobretudo pela capacidade de mobilizar, fazer fé, comprometer, envolver;

e) realizar-se é saber ceder; toda convivência participativa, se, de um lado, enriquece a pessoa, porque ninguém se realiza sozinho, de outro, estar juntos é estar cercado de limites; na comunidade, somos melhor, mas temos menos.

Tomando o exemplo da felicidade, parece evidente que seja um fenômeno dialético típico, cabendolhe as qualificações acima arroladas. Os próprios poetas repetem sempre que "felicidade são momentos felizes", ou que o amor é eterno, enquanto dura. O ser humano corre todo dia atrás da felicidade, mas a realiza aos pedaços, se tanto. É momento e pode ser forte, por ser momento. Se esticarmos, entra na extensão, vira rotina. Este é o drama do amor. Começa intenso, e vai decaindo na extensão. Assim sucede no fenômeno participativo. No início, todos ou muitos prometem participar, por exemplo, num sindicato, numa associação, num partido, numa comunidade eclesial de base. Com o tempo, esfria o envolvimento e cada vez menos gente aparece. Freqüentemente, acontece que ninguém mais comparece, ficando os chefes sozinhos. Nossas assembléias gerais, como regra, são um panorama desolador: alguns "gatos pingados" sustentam o fenômeno participativo, e por vezes também se aproveitam disso para manipular os presentes.

A provisoriedade da intensidade é marca dialética natural, onde se comprova fenômeno histórico na essência: sua forma de ser é passar, não é ficar indefinidamente. Temos a propensão de esperar da história a extensão esticada, mas que não passa de rotina.

*** Não segue destas considerações que criatividade seja mera “inspiração”. Segue apenas que inspiração não pode ser cotidiana 
Na verdade, esta é necessária, porque não se pode viver, todo dia, de criação total, invenção de tudo de novo. "Nada como um dia após o outro". Mas tudo isto é mediocridade. A história que nos interessa é aquela que, sendo inevitavelmente extensa, é sacudida de maneira reiterada, teimosa, persistente pelo ímpeto de renovação. Renovar a rotina não desfaz a rotina, porque a própria renovação pode tornar-se rotineira. Mas é na utopia da renovação que nos realizamos historicamente, porque é assim que não nos vemos apenas como desgaste implacável, mas como competência de criar.

Para afrontar limites é preciso saber deles e sobretudo que somente os afrontamos limitadamente. Esta teimosia é que faz a dignidade histórica do ser humano, que não aceita ser apenas resto histórico, mas sujeito dinâmico dela. Aí está a diferença qualitativa: história como mero desgaste, ou história como desgaste atormentado pela teimosia de criar.

\section{Qualidade é difícil de gerar, e é muito mais difícil de renovar}

Trata-se de perceber o desafio crucial de não só gerar fenômeno qualitativo, como é a participação, mas sobretudo de manter a chama acesa do envolvimento político. Uma coisa é um partido grande, outra é um grande partido. Este não é necessariamente grande em número, mas em qualidade participativa, em militância, em decisão política efetiva.

Assim, de um lado aparece o repto histórico de fazer uma história marcada pela intensidade e não só pela extensão, pela mediocridade, pela reprodução. São, pois, essenciais os fenômenos da democracia, do associativismo, do sindicalismo, da emancipação coletiva, porque é neles que emerge a competência histórica de fazer e fazer-se oportunidade. Mas, de outro lado, aparece o desgaste histórico implacável, porque, na história, o que fica, é a rotina. Não existe nenhuma condição de qualquer fenômeno humano não se desgastar historicamente. A morte não contradiz a vida, pois é apenas seu contrário. Não é vida o que não morre.

Esta marca dialética faz da qualidade um desafio de resgate permanente, de tal sorte que o permanente não será mais uma situação definitiva, institucional acabada, mas a persistência da renovação. Ser competente é essencialmente saber renovar-se. É difícil, sem dúvida, por exemplo, gerar uma proposta qualitativa na escola, comprometida com a aprendizagem do aluno, com um projeto emancipatório ou com a participação de todos, inclusive da comunidade. Mas é ainda muito mais difícil manter o envolvimento sempre aceso. Na verdade, é historicamente impossível manter sempre aceso, porque todo fogo, é fogo, porque apaga. Tudo que queima, também vira cinzas. Assim, o envolvimento não pode, a rigor, ser o mesmo todo dia. Poderá voltar a ser mais ou menos o mesmo, mas depois da baixa. Se for resgatado.

Na prática, não é viável um programa permanente de qualidade permanente, porque a qualidade permanente já não é qualitativa, ao virar qualidade rotineira, extensa. O que deve ser permanente é o esforço permanente de a renovar. A qualidade total vive profundamente este drama, dentro do contexto da educação voltada para o mercado: é muito importante o envolvimento dinâmico, participativo dos recursos humanos; os "treinamentos" buscam, entre outras coisas, agitar o envolvimento de todos, fazem dinâmica de grupo, estimulam ambiente de convivência positiva, etc.; mas todos sabem o quanto é difícil manter este espírito. Qualidade total não é um produto que se tem ou se guarda, mas sobretudo uma conquista constantemente renovada.

Neste contexto, seria possível aduzir que o termo "qualidade total" é profundamente enganoso, porque desconhece ou escamoteia a dialética histórica. "Total" acaba restringindo-se ao esforço obsessivo para provocar e manter a adesão dos recursos humanos aos fins da empresa. Ao mesmo tempo, ao reconhecer-se a necessidade de atualização permanente dos recursos humanos, é incongruente imaginar que isto se torne algo "total", ocultando exatamente o desgaste inevitável do tempo. Assim, a qualidade total implica propaganda enganosa!

\section{Qualidade é decisiva, mas não mecânica}

Tem, neste sentido, a lógica do conhecimento. Este expressa uma das qualidades humanas mais significativas, tendo sido tomado, na história da filosofia, como a marca mais central do ser humana (animal rationale). Hoje, apostamos muito na força do conhecimento, tomando-o até mesmo como o "capital" decisivo da própria economia moderna. As famílias, por sua vez, zelam pelo estudo dos filhos, acreditando que seja a melhor maneira de lhes garantir um futuro melhor.

Mesmo assim, cabe reconhecer - para ser coerente com a própria lógica do conhecimento questionador - que ele é, na essência, potencialidade, disposição, prontidão. Como diz a crítica devastadora pósmoderna, o conhecimento não sabe garantir-se, porque sua presença não implica necessária ou mecanicamente, que seja efetivo. Um decisor pode dispor do conhecimento mais atualizado possível, e, mesmo assim ou à revelia, tomar uma decisão pelo avesso. Um educador pode ter doutorado em educação e, mesmo assim, ou até por causa disso, educar muito mal seus próprios filhos.

Esta marca está contida na própria verve questionadora, porque mais facilmente desconstrói, do que constrói. Tudo que o conhecimento constrói, em seguida desconstrói, por questionamento permanente e 
por impulso de inovar sempre. Somente inova, o conhecimento que não só questiona, mas sobretudo se questiona. Assim, o que o torna permanentemente inovador é a capacidade de questionar e se questionar sempre. Quer dizer, sua força está na fragilidade dialética, expressando tipicamente a dialética da potencialidade. O que é potencial, só o pode ser na medida da amplidão infinita de maneiras possíveis de vir-a-ser, mas, por conta disso, pode ser qualquer coisa, inclusive não ser. É como o "berço", aludindo-se à qualidade humana de alguém que teria sido "bem-educado": é decisivo, mas facilmente se perde.

Assim, qualidade humana representa o que há de mais intenso, profundo, perfeito que o ser humano pode construir, mas daí não seguem efeitos automáticos ou mecânicos, precisamente porque estes não são, em si, "humanos". Sem um naipe qualitativo de professores, não há aprendizagem adequada dos alunos. Isto é certo, talvez o que haveria de mais certo. Entretanto, é possível que uma professora mal preparada alfabetize melhor as crianças do que uma especialista mundialmente reconhecida, assim como parece ser o caso no Brasil de um desempenho mais convincente da normalista, comparado ao licenciado, embora este, por deter mais anos de estudo, devesse "educar" melhor.

No plano político, esta problemática é por vezes muito evidente, por exemplo, quando se defende que, para ser Presidente da República, não se exigem títulos acadêmicos, a não ser certo limite de idade e alguma escolaridade mínima, além de requisitos de comportamento público. Não caberia defender que o Presidente devesse ter doutorado em administração pública, como estaríamos dispostos a defender que o Lula pode ser Presidente, mas não professor. $\mathrm{Na}$ verdade, estamos procurando no Presidente principalmente uma qualidade política, que não se expressa necessariamente por externalidades, como anos de estudo ou montante de riqueza. Do que se trata?:

a) é mister distinguir entre instrumentações formais e materiais da qualidade, da qualidade política como tal; esta necessita daquelas, mas a elas não se restringe; assim, um doutor em educação não é automaticamente um bom educador;

b) como qualquer potencialidade, sua direção histórica não está predeterminada, mas efetivada de acordo com o envolvimento ideológico e ético em jogo; assim, professores bem preparados formalmente podem apresentar um desempenho, em termos de aprendizagem dos alunos, pior que outros tidos por mal preparados;

c) toda qualidade humana paga o preço da liberdade e do risco histórico; ou seja, sendo dialética potencial, é dúbia, frágil, em grande parte imprevisível; é tudo que podemos desejar, mas nunca é tudo que podemos fazer, além de gastar-se com extrema velocidade; d) usando linguagem da lógica clássica, qualidade humana é condição necessária, mas não suficiente de uma história humana; dialeticamente falando, não existem condições suficientes na história, por não serem propriamente históricas; história é precisamente o horizonte das possibilidades inesgotáveis, não um tabuleiro de carta marcada.

\section{A história da qualidade é sobretudo de sua traição}

Traição vem compreendida no duplo sentido dialético: de um lado, daquilo que, sendo intensamente bom, degenera no extensamente ruim; de outro, da infidelidade ao cotidiano, para ser criativa. O cotidiano chora, como se diz em antropologia, porquanto é feito sobretudo de tristeza, mesmice, repetição, mediocridade. Tal qual o bom menino, que é considerado bom porque nada inventa. Perfeitamente medíocre.

O cotidiano pode ser visto como a traição de cada dia da utopia da vida, onde viver já é quase só vegetar, apenas passar pela vida, ser espectador, ou mero objeto. Por outra, para confrontar-se com o cotidiano, é mister saber traí-lo. A criatividade é sempre um ato de infidelidade, como é a ciência crítica. Para inovar, é mister desconstruir, desfazer, recomeçar. Destruir uma rotina que a tudo destrói, é o desafio maior da qualidade, que precisa trair o cotidiano, para não ser sempre traída. A estratégia da qualidade é principalmente a vigilância obsessiva contra a mesmice institucional, que faz tudo repetir-se para ficar na mesma.

A vida em sociedade é sobretudo uma estratégia de acomodação, de tal sorte que cada dia é o mesmo dia. Predomina, de longe, a pressão pela conformidade, sobre o esforço de criatividade. Todos esperam que cada qual cumpra com seu dever, ou seja, não invente moda, não pretenda ser diferente, não discrepe. Mediocridade geral é a sina da convivência humana. A fidelidade às normas e valores, levada a extremos, decreta a descaracterização de um ser humano criativo.

Assim como a morte é a traição da vida, a vida como mera repetição é a traição da felicidade. Por isso, a maneira de esticar a felicidade não é prolongá-la extensamente, mas interrompê-la estrategicamente. Ressuscita melhor o que sabe morrer. Não pode ser vida o prolongamento da agonia. O amor vira rotina, invariavelmente, não tanto como defeito, mas como marca histórica natural. Qualidade é a luta, por vezes desesperada, de retomar uma intensidade que teima em transformar-se em extensão. Não há receita para esta retomada, mas parece certo que é mister trair. Bem entendido, trair no sentido de surrupiar do cotidiano chato momentos felizes. Até porque a fidelidade pode ser apenas extensa, sempre que decair no relacionamento repetido, mecânico, formal. É neste sentido que se deve 
dizer: todo projeto criativo, continuará criativo, se encontrar traidores. $\mathrm{O}$ traidor pode ser aquele que apenas se opõe ao projeto. Mas o traidor aqui procurado é quem é infielmente fiel à criatividade.

\section{C) Qualidade formal e política}

No campo educativo, convém distinguir duas dimensões da qualidade, que, na prática, aparecem globalizadas: o lado formal e o lado político.

\section{Qualidade Formal}

Por qualidade formal compreendemos a perfeição dos meios, dos instrumentos, dos procedimentos, e se refere substancialmente ao conhecimento. Este é o instrumento mais efetivo de inovação histórica, ou seja, é a arma mais potente de renovação de uma história que teima sempre em se desgastar ${ }^{51,52,55}$.

Entretanto, o próprio conhecimento representa, nele mesmo, a provisoriedade de uma história renovada. Sendo, na essência, uma estratégia de questionamento, tem sua virtude principal no método, mais do que na fabricação de conteúdos. Estes sempre envelhecem, por serem históricos. O que não envelhece é a capacidade de se opor permanentemente ao envelhecimento. Esta competência de sempre se renovar é a competência humana mais típica e relevante.

O exemplo dos computadores é paradigmático. Todo modelo novo é feito para ser superado. Não é viável um computador definitivo. $\mathrm{O}$ que faz dele uma máquina interessante é que implica, nela mesma, a necessidade de incessante renovação. Este exemplo é interessante também porque denota uma face preocupante da renovação, ligada à dinâmica do mercado. Renova-se tanto a informática, porque é essencial à produtividade moderna, não principalmente porque é importante para a história humana. O que é crucial para a humanização da história renova-se menos do que o que é essencial para o mercado. Isto quer dizer que nossa história conhecida representa, diante do mercado, uma subalternidade que deveríamos, com o tempo, saber também superar ${ }^{13,35}$.

Mas isto não desfaz o desafio de atualização permanente, tão típico do conhecimento moderno. A própria marca do questionamento leva a isto, tanto por uma necessidade lógica, quanto por uma necessidade democrática ${ }^{24,27,46}$. O conhecimento, que funciona pela via do questionamento, somente é coerente consigo mesmo se souber sobretudo se questionar. A lógica do questionamento é a mesma do auto-questionamento, porquanto a competência da crítica está na autocrítica. Por outra, questionar implica reconhecer o direito de todos de falar, seja porque qualquer consenso somente subsiste se for democrático, seja porque a reserva de conhecimento é sempre excludente e nisto afoga o questionamento.

Esta característica levou a reconhecer que conhecimento perdeu seu valor de uso. Somente o conhecimento que se renova vale a pena e serve para renovar. Guardar conhecimento, estocar, armazenar, apropriar-se dele, adquirir, são expectativas arcaicas, que, na prática, desfazem a virtude inovadora do conhecimento. O que interessa é a reconstrução do conhecimento, porque conhecer é substancialmente reconstruir conhecimento ${ }^{7,10,37,69}$. O que mais inova é também o que mais envelhece. O que mais e melhor traz novidades na história, é também aquilo que a torna tanto mais provisória. A velocidade das grandes mudanças se acelera cada vez mais. O que se via em mil anos, hoje pode ser vivenciado numa geração.

Aí temos, pois, um caminho da qualidade essencial para a educação. Se quiser manejar a capacidade de inovar a história, de intervir nela como sujeito que a faz, de fazer e fazer-se oportunidade, o ser humano precisa manejar conhecimento. Em termos instrumentais, eis o instrumento maior e melhor. Espera-se, por isso, que a criança aprenda de fato na escola, ou seja, construa formação básica capaz de saber pensar para melhor intervir. Esta habilidade propedêutica é crucial para dar conta dos desafios da modernidade e, como veremos, sobretudo para educar a modernidade. Ler a realidade com competência é a forma mais efetiva de nela intervir alternativamente ${ }^{15,31}$.

Supera-se com isto a tradição do mero repasse de conhecimento. $\mathrm{O}$ aluno não vai à escola para adquirir conhecimento, ou apropriar-se dele, ou para assimilá-lo, mas estritamente para reconstruí-lo. O que o torna oportunidade histórica, em termos instrumentais, é principalmente esta habilidade. De apenas escutar, tomar nota e fazer prova, ninguém fica competente. Ao contrário, é a rota clássica da subalternidade. É ser resto do outro mundo que sabe reconstruir conhecimento. Assim, enquanto o Primeiro Mundo pesquisa, o Terceiro dá aula!

\section{Qualidade Política}

Todo instrumento encontra sentido na finalidade a que serve. Conhecimento não vale por si nem em si, mas como meio para realizar os fins e os valores sociais, em termos do bem comum. Qualidade política tem a ver principalmente com a ética do conhecimento, da história, das intervenções ${ }^{3,4,70}$.

É sempre possível reconstruir o melhor conhecimento possível para imbecilizar, torturar, destruir. Esta preocupação é forte hoje em muitos críticos da ciência, porque, ao lado da instrumentalidade fantástica que coloca à disposição do ser humano, representa também risco forte de exclusão. A ciência costuma crescer 
tanto mais por força do mercado ou servindo aos poderosos, não pela ética do bem comum ${ }^{51,52,57,84}$.

Aqui entra em cena a necessária ética do ser humano que não só sabe inovar, mas sobretudo sabe humanizar a inovação. Sabe fazer uma história humana, com base na competência humana. Para tanto, necessita do conhecimento, porque é o meio mais efetivo. Não pode haver um sujeito histórico competente que não saiba manejar conhecimento. Mas esta competência não é tudo. É apenas instrumental. Há ainda que incutir a devida ética.

Trata-se, pois, da cidadania, compreendida como a competência de tomar, pela consciência crítica, a história nas mãos e torná-la bem comum. E esta é a meta central do processo educativo, ou seja, de gestar sujeitos históricos devidamente instrumentados no conhecimento, para intervir melhor na história. Intervir melhor significa precisamente não permanecer apenas na intervenção, mas fazer dela bem comum.

A definição de qualidade pode parecer um jogo teórico. Entretanto, como nada é melhor para a prática do que uma boa teoria, será o caso perceber que nenhuma prática da qualidade é qualitativa se não souber definirse conceitualmente. Acaba tornando-se "qualquer coisa".

Um exemplo disso está nos treinamentos comuns na "qualidade total". Por não usar conceitos adequados de qualidade, passa-se a admitir que a competência humana provenha de meros treinamentos, que tratam a pessoa humana como objeto de ensino. Estritamente, repassa-se conhecimento, esperando que os recursos humanos o absorvam, internalizem, transformem em conduta, de fora para dentro. Nada é mais contraditório com a condição de sujeito ou de qualidade humana do que ser objeto.

A qualidade total, freqüentemente, esvai-se em táticas de adesismo, através da qual busca-se envolver os trabalhadores na dinâmica da empresa. Esta precisa de conhecimento renovador e sobretudo de gente que saiba manejar conhecimento renovador. Mas, com base em noção truncada de cidadania, privilegia-se e por vezes exclusiviza-se a relação com o mercado. Aumenta-se a oportunidade de lucro e produtividade, mas dificilmente melhora-se a condição do trabalhador.

Treinamento é uma iniciativa incapaz de gestar autêntica formação básica, compreendida esta como a capacidade de saber pensar para melhor intervir, na interseção entre qualidade formal e política. Fica-se apenas com a qualidade formal, se tanto. Treinamento nem isto faz, porque permanece com a cópia do conhecimento, não impulsionando sua reconstrução. Evita-se a qualidade política, que somente é factível no berço da educação emancipatória.

Uma definição mais acurada supera a noção de qualidade como fumaça esgarçada num horizonte impreciso, permitindo inclusive localizá-la concretamente em fenômenos específicos, como o da participação, educação, democracia, comunidade, etc. Pode-se também apontar caminhos concretos de como se gesta e resgata qualidade, em termos formais e políticos, dentro do contexto do manejo instrumental do conhecimento e de sua implicação ética.

Ao mesmo tempo, pode-se evitar o discurso perdido e lunático em torno da qualidade, comum a educadores que não ultrapassam o nível persistente das "considerações gerais". Qualidade não pode ser apenas problema teórico. É sobretudo desafio prático. "Saber fazer e refazer qualidade" - eis a questão. Pelo fato de educação, por mais intensa que seja sua qualidade, não produzir efeitos mecânicos e automáticos, disto não decorre que seja algo intangível. A intensidade que melhor se pode ver, é aquela que também melhor se define.

Esta definição mais acurada de qualidade pode colaborar em especificar melhor os objetivos pretendidos em educação, bem como em avaliar com profundidade mais convincente a intensidade de fenômenos considerados estratégicos, como a formação básica. Não cabe, por exemplo, permanecer apenas em expressões quantitativas, como meros anos de estudo, bem assim em expressões apenas formais de testes, como rendimento escolar mensurado por testes de conhecimento. Será possível perseguir melhor dimensões mais substanciais como o saber pensar para melhor intervir e inovar, compondo qualidade formal e política. Quando criticamos didáticas reprodutivas, acenamos para o desafio reconstrutivo, que se compõe melhor com processos emancipatórios do sujeito e da formação histórica de sociedades alternativas. Se é dificílimo avaliar qualidade política, podemos pelo menos orientar avaliações da qualidade formal na esteira de instrumentações da qualidade política.

A qualificação do cidadão e do trabalhador não se esgota em treinamentos estereotipados, mas precisa evoluir para a idéia de alimentação constante da empregabilidade e da atuação política organizada. Ao mesmo tempo que podemos mostrar, estatisticamente, que é o fator preponderante do acesso à renda, seria ainda mais importante revelar que é o apoio mais decisivo de uma cidadania capaz de redistribuí-la. Não basta, assim, preocupar-se só com salário e treinamento dos professores, porque é sobretudo fundamental garantir a relação intrínseca com a aprendizagem adequada dos alunos. Olhando assim, podemos logo concluir que treinamento nunca faz isto, e que salário pode não ter nada, mas pode ter tudo a ver com a aprendizagem dos alunos. Porquanto, se o professor não for a prova viva da cidadania, ou seja, a prova de que educação leva à cidadania, incluindo-se aí obviamente a dignidade salarial, não tem como contribuir para a formação da cidadania do aluno. 


\section{PESQUISA QUALITATIVA - USOS E ABUSOS}

Fizemos no capítulo anterior um esforço de sistematização do conceito de qualidade, dentro da coerência científica formalizante. Enquanto qualidade for qualquer coisa, pesquisa qualitativa também o será. Como se viu, é dificílimo traçar relevos da qualidade e mesmo assim é essencial defini-la em termos lógico-formais. Tais definições devem ser vistas como instrumento metodológico, não como aprisionamento formal. Vale aqui a regra clássica da hermenêutica: muitas vezes é mais relevante o que está oculto, o que não se diz, o que se esconde.

Pesquisa qualitativa significa, na esteira de nossa argumentação, o esforço jeitoso de formalização perante uma realidade também jeitosa. Trata-se de uma consciência crítica da propensão formalizante da ciência, sabendo indigitar suas virtudes e vazios. Portanto, o que se ganha e se perde com cada método. Ao mesmo tempo, uma pesquisa qualitativa dedica-se mais a aspectos qualitativos da realidade, ou seja, olha prioritariamente para eles, sem desprezar os aspectos também quantitativos. E vice-versa.

Se tomássemos o exemplo de uma análise do discurso, o que buscamos é sobretudo suas implicações hermenêuticas, que facilmente nos escapam ou são invisíveis/imperceptíveis, quando não agem exatamente pela ausência ou pelo silêncio. Esta realidade tão forte quanto arredia pode ser nosso objeto de análise. Entretanto, para chegarmos lá, é mister antes catalogar o discurso, fazer uma exegese de frases e palavras, quantificar recorrências, vocábulos, expressões mais freqüentes, não para ficarmos aí, mas vermos melhor a partir daí. Assim, quem sistematiza melhor, pode ter vantagem. Um questionário aberto pode ser a porta de entrada para um mundo de representações sociais mais subjetivas, e por isso mais profundas e determinantes, à medida que permite a fala descontraída, realista e natural, a não-linearidade de respostas sobre realidades tipicamente não-lineares. Mas, ainda assim ou precisamente por isso, precisa ser bem organizado e garantir, entre outras coisas, que em cada novo questionário se trata do mesmo tema, da mesma pesquisa, da mesma análise, ou seja, deve existir um contexto sistemático e lógico, até mesmo para podermos comparar e inferir. É erro crasso imaginar que de conversas soltas, amadoramente conduzidas ou mal conduzidas, se possa extrair alguma análise mais profunda, ou que de algumas pessoas indagadas se possa inferir conclusões que abalem o universo. Ademais, se no dado empírico, quantitativo ou pretensamente quantitativo, a manipulação corre solta, que dizer de dados qualitativos desprovidos de um mínimo de sistematização...

Hoje podemos dizer - de boca cheia - que a qualidade está em primeiro lugar, seja pelas quimeras da qualidade total, seja pela saturação dos métodos excessivamente formalizantes e nisso empobrecedores da realidade, seja porque precisamos avançar em horizontes tão intensos, quanto difíceis de devassar. As ciências físicas e biológicas acenam com uma aproximação sem precedentes. Todavia, não vai valer a pena trocar um exagero, por outro.

Por fim, algo intrigante: grandes autores voltados para realidades mais qualitativas, como Habermas e as dimensões de seu "mundo da vida", ou os pesquisadores da inteligência, ou os biólogos e físicos que buscam perscrutar a "capacidade de aprendizagem da matéria" e de todo ser vivo, não recorrem aos ditos "métodos qualitativos" que os cientistas sociais valorizam. Chomsky, por exemplo, reconhecido hoje como um dos autores mais sensíveis à qualidade democrática dos Estados e governos, não usa tais metodologias. Muitas vezes se assacou contra pesquisadores latino-americanos que gostam de pesquisa qualitativa a acusação de que seria "coisa do Terceiro Mundo". De fato, o mundo desenvolvido a maneja apenas marginalmente. A própria ONU em seus Relatórios sobre Desenvolvimento Humano, expressamente voltados para a qualidade humana da população, faz tudo isso com indicadores clássicos, embora reconstruídos sob outros horizontes. Inclusive faz-se um índice de desenvolvimento humano, que, a rigor, não pode ser medido.

Sucede, a nosso ver, que tais pesquisadores nunca abandonaram as vantagens da formalização científica, quando feita com juízo. O índice de desenvolvimento humano expressa muito menos uma "medida", do que um composto de traços qualitativos numericamente construídos. Neles exala-se menos a extensão, do que a intensidade do bem-estar. No fundo, temos o mesmo caso nas notas que damos aos alunos. Alguns querem uma "menção", porque seria menos agressiva, ao não parecer "medida". Na prática é medida, com todas as letras. E quando necessitamos de médias, reduzimos menções a notas. Achar que "sem rendimento" ofende menos que "zero", é um prurido tolo, razão pela qual menção e nota são perfeitamente sinônimos. O que buscamos com a menção é o mesmo que com a nota: uma expressão numérica, para fins de avaliação, de um composto de qualidades que um aluno tem. A expressão é posta em termos numéricos para tornar-se mais visível e talvez compreensível $^{30}$.

Não faria mal se os pesquisadores sociais, por reconhecimento aos bons ventos que sopram do "lado oposto", também valorizassem mais as habilidades formalizantes da metodologia científica. Muitas vezes, adotamos certos modismos metodológicos, porque desconhecemos o cardápio variado disponível orientado para realidades qualitativas, como hermenêutica e fenomenologia, já tradicionais. 


\section{QUALITATIVE RESEARCH \\ SEARCH FOR EQUILIBRIUM BETWEEN FORM AND CONTENT}

The present study describes the change of expectation regarding qualitative research through post modernity evolution. The author focus on quality under several aspects, pointing out the practices and abuses in qualitative research.

\section{PESQUISA CUALITATIVA BUSCA DE EQUILÍBRIO ENTRE FORMA E CONTEÚDO}

Este artículo presenta una descripción del cámbio de espectativa en lo que se refiere a la investigación cualitativa a través de la evolución de la post-modernidad. Enfoca la calidad sobre vários aspectos, apontando hacia los usos y abusos en la investigación cualitativa.

TÉRMINOS CLAVES: investigación, investigación cualitativa

\section{REFERÊNCIAS BIBLIOGRÁFICAS}

01. ALBERONI, F.; VECA, S. O altruísmo e a moral. Rocco: Rio de Janeiro, 1990.

02. ANDRADE, H.G. Morte, renascimento, evolução: uma biologia transcendental. São Paulo: Pensamento, 1983.

03. APEL, K.O. Diskurs und Verantwortung - Das Problem des Übergangs zur Postkonventionellen Moral. Suhrkamp, Frankfurt: Suhrkamp, 1988.

04. APEL, K.O. Estudos de moral moderna. Petrópolis: Vozes, 1994.

05. BACHELARD, G. O direito de sonhar. São Paulo: DIFEL, 1986.

06. BARROW, J.D. Teorias de tudo - a busca da explicação final. Rio de Janeiro: Jorge Zahar, 1994.

07. BASTOS, C.; KELLER, V. Aprendendo a aprender - introdução à metodologia científica. Petrópolis: Vozes, 1992.

08. BAUDRILLARD, J. 1992. Da sedução. apud. BATAILlE, G. O erotismo. São Paulo: L \& M, 1987.

09. BOHM, D.; PEAT, F.D. Ciência, ordem e criatividade. Lisboa: Gradiva, 1989.

10. BOMBASSARO, L.C. As fronteiras da epistemologia - como se produz o conhecimento. Petrópolis: Vozes, 1992.

11. BROWN, R. Analisando o amor. Campinas: Papirus, 1990.

12. BRUHNS, H.T. O corpo parceiro e o corpo adversário. Campinas: Papirus, 1993.

13. BRUNHOFF, S. A hora do mercado - crítica do liberalismo. São Paulo: Editora UNESP, 1991.
14. BUENO, E.F.; PRADO, J.S.A. Educação emocional - a arte de unir-se. São Paulo: Cortez, 1989.

15. CARRAHER, T.N. (Org.). Aprender pensando contribuições da psicologia cognitiva para a educação. Petrópolis: Vozes, 1988.

16. CERTEAU, M. A invenção do cotidiano - artes de fazer. Petrópolis: Vozes, 1994.

17. COULON, A. Etnometodologia e educação. Petrópolis: Vozes, 1995a.

18. CSIKSZENTMIHALYI, M. A psicologia da felicidade. São Paulo: Saraiva, 1992.

19. DAMÁSIO, A.R. O erro de descartes - emoção, razão e o cérebro humano. São Paulo: Companhia das Letras, 1996.

20. DEMO, P. Investigación participante - mito y realidad. Buenos Aires: Kapelusz, 1985.

21. DEMO, P. Ciencias sociales y Ccalidad. Madrid: Narcea, 1988.

22. DEMO, P. Dialética e qualidade política. In: Haguette, T.M.F. (Org.). Dialética Hoje, Petrópolis: Vozes, 1990, p. 116 ss.

23. DEMO, P. Cidadania menor - algumas indicações quantitativas de nossa pobreza política. Petrópolis: Vozes, 1992.

24. DEMO, P. Pesquisa e construção do conhecimento - metodologia científica no caminho de habermas. Rio de Janeiro: Tempo Brasileiro, 1994.

25. DEMO, P. ABC - Iniciação à competência reconstrutiva do professor básico. Campinas: Papirus, 1995a.

26. DEMO, P. Cidadania tutelada e cidadania assistida. Campinas: Autores Associados, 1995b.

27. DEMO, P. Desafios modernos da educação. Petrópolis: Vozes, 1995c. 
28. DEMO, P. Educação e qualidade. Campinas: Papirus, 1995d.

29. DEMO, P. Metodologia científica em ciências sociais. São Paulo: Atlas, 1995e.

30. DEMO, P. Avaliação - sob o olhar propedêutico. Campinas: Papirus, 1996a.

31. DEMO, P. Educar pela pesquisa. Campinas: Autores Associados, 1996b.

32. DEMO, P. Conhecimento moderno. Petrópolis: Vozes, 1997.

33. DREIFUSS, R.A. A época das perplexidades mundialização, globalização e planetarização: novos desafios. Petrópolis: Vozes, 1996.

34. FRANÇA, M.I. (Org.). 1995. Desejo, barbárie e cidadania. Petrópolis: Vozes, 1995.

35. FRIGOTTO, G. Educação e a crise do capitalismo real. São Paulo: Cortez, 1995.

36. GAARDER, J. O mundo de Sofia - romance da história da filosofia. São Paulo: Companhia das Letras, 1995.

37. GARCIA, F.L. Introdução crítica ao conhecimento. Campinas: Papirus, 1988

38. GARDNER, H. Estruturas da mente - a teoria das inteligências múltiplas. Porto Alegre: Artes Médicas, 1994.

39. GAY, P. A Educação dos sentidos - a experiência burguesa da rainha Vitória a Freud. São Paulo: Companhia das Letras, 1989.

40. GAY, P. A paixão terna - a experiência burguesa da rainha Vitória a Freud. Rio de Janeiro: Companhia das Letras, 1990. v.2

41. GENTILI, P. (Org.). 1995. Pedagogia da exclusão crítica ao neoliberalismo em educação. Petrópolis: Vozes, 1995.

42. GENTILI, P.A.A.; SILVA, T.T. (Org.). Neoliberalismo, qualidade total e educação. Petrópolis: Vozes, 1995.

43. GOLEMAN, D. Inteligência emocional - a teoria revolucionária que redefine o que é ser inteligente. Rio de Janeiro: Objetiva, 1996.

44. GONÇALVES, M.A.S. Sentir, pensar, agir corporeidade e educação. Campinas: Papirus, 1994.

45. GUATTARI, F.; ROLNIK, S. Micropolítica cartografia do desejo. Petrópolis: Vozes, 1993.

46. HABERMAS, J. Consciência moral e agir comunicativo. Rio de Janeiro: Tempo Brasileiro, 1986.

47. HAMMER, M.; CHAMPY, J. Reengenharia revolucionando a empresa. São Paulo: Campus, 1994.

48. HELLER, A. Para mudar a vida - felicidade, liberdade e democracia. São Paulo: Brasiliense, 1982.
49. HUIZINGA, J. 1980. Homo Ludens. São Paulo: Perspectiva, 1980.

50. INGRAM, D. Habermas e a dialética da razão. Brasília: Editora UnB, 1994.

51. LÉVY, P. As tecnologias da inteligência - o futuro do pensamento na era da informática. São Paulo: Editora 34, 1995.

52. LÉVY, P.; AUTHIER, M. As árvores de conhecimento. São Paulo: Escuta, 1995.

53. LIFTON, R.J. O futuro da imortalidade - ensaios para uma era nuclear. São Paulo: Trajetória, 1989.

54. LlOYD, C. As estruturas da história. Rio de Janeiro: Jorge Zahar, 1995.

55. LOJIKINE, J. A revolução informacional. São Paulo: Cortez, 1995.

56. LUHMANN, N. O amor como paixão - para a codificação da intimidade. Rio de Janeiro: DIFEL, 1991.

57. LYOTARD, J.F. La condición postmoderna informe sobre el saber. Tese (Catedra) Madrid, 1989.

58. MARKERT, W. (Org.). Teorias de educação do iluminismo, conceitos de trabalho e do sujeito. Rio de Janeiro: Tempo Brasileiro, 1994.

59. MARX, K. Contribuição para a crítica da economia política. Lisboa: Estampa, 1973.

60. MATOS, O.C.F. Os arcanos do inteiramente OUTRO - a escola de Frankfurt, a melancolia e a revolução. São Paulo: Brasiliense, 1989.

61. MATURANA, H.; VARELA, F. De máquinas y seres vivos - autopoiesis: la organización de lo vivo. Santiago: Editorial Universitaria, 1995a.

62. MATURANA, H.; VARELA, F. El árbol del conocimiento. Santiago: Editorial Universitaria, 1995b.

63. MATURANA, H. R.; VARELLA, F. Autopoiesis and cognition: the realization of the living. Reidel: Dordrecht, 1980.

64. MATURANA, H.R. Biology and Language: The epistemology of reality. In: G.A. Miller and E. Lenneberg (Eds.). Psychology and biology of language and thoutht: essays in honor of Eric Lenneberg. New York: Academic Press, 1978. p. 27-64.

65. MCNEELY, D.A. Tocar - terapia do corpo e psicologia profunda. São Paulo: Cultrix, 1987.

66. MOLES, A.A. 1996. As ciências do impreciso. Rio de Janeiro: Civilização Brasileira, 1996.

67. MORIN, E. Introdução ao pensamento complexo. Lisboa: Instituto Piaget, 1995.

68. MORIN, E. Ciência com consciência. Rio de Janeiro: Bertrand Brasil, 1996. 
69. OLIVA, A. (Org.). Epistemologia: a cientificidade em questão. Campinas: Papirus, 1990.

70. OLIVERIA, M.A. Ética e sociabilidade. São Paulo: Loyola, 1993.

71. PASSERON, J.C. O racionalismo sociológico - o espaço não-popperiano do raciocínio natural. Petrópolis: Vozes, 1995.

72. PNUD/ONU. Human development Report. New York: ONU, 1995.

73. POPPER, K.R. The logic of scientific discovery. Hutshinson of London, 1959.

74. POPPER, K.R. El desarrollo del conocimiento científico - conjeturas y refutaciones. Paidos, Buenos Aires, 1967.

75. POPPER, K.R. Objective knowledge - an evolutionary approach. Oxford: Clarendon Press, 1972.

76. POPPER, K.R. Em busca de um mundo melhor. Lisboa: Fragmentos, 1989.

77. PORTER, M.E. Estratégia competitiva - técnicas para análise de indústrias e da concorrência. São Paulo: Campus, 1991.

78. PRIGOGINE, I. 1996. O fim das certezas - tempo, caos e as leis da natureza. São Paulo: Ed. UNESP, 1996.

79. RAMOS, C. Excelência na educação - a escola de qualidade total. Rio de Janeiro: Qualitymark, 1993.

80. RAMOS, C. Pedagogia da qualidade total. Rio de Janeiro: Qualitymark, 1994.
81. RAMOS, C. Sala de aula de qualidade total. Rio de Janeiro: Qualitymark, 1995.

82. RIFKIN, J. Fim dos empregos - o declínio inevitável dos níveis dos empregos e a redução da força global de trabalho. São Paulo: Makron Books, 1996.

83. SAFOUAN, M. O fracasso do princípio do prazer. Campinas: Papirus, 1988.

84. SANTOS, B.S. Introdução a uma ciência pósmoderna. São Paulo: Graal, 1989.

85. SIBONY, D. Sedução - o amor inconsciente. São Paulo: Brasiliense, 1991.

86. SIEBENEICHLER, F.B. Jürgen habermas - razão comunicativa e emancipação. Rio de Janeiro: Tempo Brasileiro, 1989.

87. SIMMEL, G. Filosofia do amor. Lisboa: Martins Fontes, 1993.

88. TAN, A. O clube da felicidade e da sorte. Rio de Janeiro: Rocco, 1991.

89. TEIXEIRA, F.J.S. E OLIVEIRA, M.A. (Orgs.). Neoliberalismo e reestruturação produtiva as novas determinações do mundo do trabalho. São Paulo: Cortez, 1996.

90. THIOLLENT, M. Metodologia da pesquisa-ação. São Paulo: Cortez, 1986.

91. WINOGRAD, T.; FLORES, F. Understanding computers and cognition: a new foundation for design. New Jersey: Ablex Publishing, 1986. 